\title{
Occipitocervical contoured rod stabilization: Does it still have a role amidst the modern stabilization techniques?
}

\author{
Samir K. Kalra, Vijendra K. Jain, Awadesh K. Jaiswal, Sanjay Behari \\ Department of Neurosurgery, Sanjay Gandhi Postgraduate Institute of Medical Sciences, Lucknow - 226014, India
}

\begin{abstract}
Background: The occipitocervical contoured rod (CR) stabilization for use in craniovertebral junction (CVJ) pathologies is an effective and economical technique of posterior fusion (PF). Aims: The various indications for CR in CVJ pathologies are discussed. Settings and Design: Retrospective analysis. Materials and Methods: Fifty-four patients (mean age: $31.02 \pm 13.44$ years; male: female ratio=5.75:1) who underwent $C R$ stabilization are included. The majority had congenital atlantoaxial dislocation (AAD; $\mathrm{n}=50$ ); two had CVJ tuberculosis; one each had rheumatoid arthritis and C2-3 listhesis, respectively. The indications for $\mathrm{CR}$ fusion in congenital AAD were associated Chiari 1 malformation (C1M) $(n=29)$; occipitalized $C 1$ arch and/or malformed or deficient $C 1$ or C2 posterior elements $(n=9)$; hypermobile AAD $(n=2)$; and, rotatory $\operatorname{AAD}(n=3)$. Contoured rod as a revision procedure was also performed in seven patients. Most patients were in poor grade (18 in Grade III [partial dependence for daily needs] and 15 in Grade IV [total dependence]); 15 patients were in Grade II [independent except for minor deficits] and six in Grade I [no weakness except hyperreflexia or neck pain]. Results: Twenty-four patients improved, 18 stabilized and six deteriorated at a mean follow-up (FU) of $17.78 \pm 19.75$ (2-84) months. Six patients were lost to FU. In 37 patients with a FU of at least three months, stability and bony union could be assessed. Thirty-one of them achieved a bony fusion/ stable construct. Conclusions: Contoured rod is especially useful for PF in cases of congenital AAD with coexisting CIM, cervical scoliosis, sub-axial instability and/or asymmetrical facet joints. In acquired pathologies with three-column instability, inclusion of joints one level above the affected one by using $\mathrm{CR}$, especially enhances stability.
\end{abstract}

Key words: Atlantoaxial dislocation, contoured rod, craniovertebral junction, posterior fusion

The craniovertebral junction (CVJ) represents a unique and complex interface responsible for more than half of the rotation and flexion-extension of the cervical spine. The osseous articulations and their supporting ligaments must resist forces in all axes of motion. ${ }^{[1-5]}$ Various pathological conditions can destabilize this junction. The surgical goal, therefore, is relief of neural compression and stabilization. ${ }^{[6-9]}$

Occipitocervical fusion was first described by Forrester in 1927. ${ }^{[9]}$ All internal fusion techniques focus on providing rigid constructs to facilitate bony fusion and reduce the need for and the duration of external immobilization. . $^{[2,3,5,7,9-11]}$

The various techniques of posterior stabilization of CVJ are classified into those that use 1) Methylmethacrylate; 2) Occipitocervical plates and screws; 3) Contoured rod (CR) with wires; 4) Metallic clamps; and, 5) Transarticular screws. Autologous bone graft promotes a good bony union. The long-term stabilization depends on bony integration. ${ }^{[10-20]}$

The Ransford's occipitocervical CR fusion method first reported in 1986 has stood the test of time as an effective and economical method of posterior stabilization. ${ }^{[19]}$ The technique involves fixing a prefabricated loupe to the occiput and the upper cervical laminae using sublaminar wires. ${ }^{[6,8,9]}$ The first description of the technique in India was by Das et al. ${ }^{[12]}$ The basic method has remained constant albeit with minor modifications including threaded pins, interspinous wiring, shape variations and the use of magnetically inert materials. ${ }^{[9,11,14,20,21]}$

Despite the emergence of several new occipitocervical fusion techniques, ${ }^{[8-10,15,17,22,23]} \mathrm{CR}$ fusion is still one of most economical and versatile methods that is especially useful in certain specific situations. This study focuses on the indications, outcome, advantages and drawbacks in using CR fusion.

\section{Materials and Methods}

\section{Patient spectrum}

Fifty-four consecutive patients (mean age: $31.02 \pm$ 13.44 years; range 3-65 years; male: female ratio $=5.75: 1)$ 
who underwent CR fusion in past 10 years (January 1997 to 2006) were included and analyzed retrospectively. The complete patient information was recorded prospectively on prescribed proformas as a part of ongoing protocol on CVJ pathologies. The majority of them had congenital atlantoaxial dislocation (AAD; $\mathrm{n}=50$ ). Their associated anomalies are presented in Tables 1a and 1b. The indications for using CR were coexisting Chiari 1 malformation $(\mathrm{C} 1 \mathrm{M})(\mathrm{n}=29)$; occipitalized C1 arch and/or malformed or deficient $\mathrm{C} 1$ or $\mathrm{C} 2$ posterior elements $(\mathrm{n}=9)$; hypermobile AAD $(\mathrm{n}=2)$; and, rotatory AAD with compensatory subaxial scoliosis $(\mathrm{n}=3)$.

Also included were those patients who underwent CR during revision surgery $(\mathrm{n}=7)$. Two patients having irreducible AAD with basilar invagination (BI), C1M and syringomyelia underwent posterior decompression at another center [Figures 1a and b]. Following their neurological deterioration at follow-up, a transoral decompression (TOD) and CR stabilization was performed. Three patients with irreducible AAD and BI underwent transoral surgery with occipitocervical fusion using Jain's technique. ${ }^{[1,3]}$ They did not improve due to residual posterior bony compression $(n=2)$; or, both anterior and posterior bony compression $(n=1)$. The patients who had previously undergone only posterior decompression underwent a repeat posterior stabilization using CR. The one patient who had previously undergone both anterior and posterior decompression underwent a revision single-stage TOD and CR.

Two patients having reducible AAD also underwent a revision CR fusion. One of them had associated C1M with syringomyelia for which posterior decompression had already been performed elsewhere. He underwent CR stabilization due to persisting reducible C1-2 dislocation. The other patient had an initial posterior C12 sublaminar fusion and did not improve. His intrathecal contrast enhanced computed tomographic scan (ITCT)
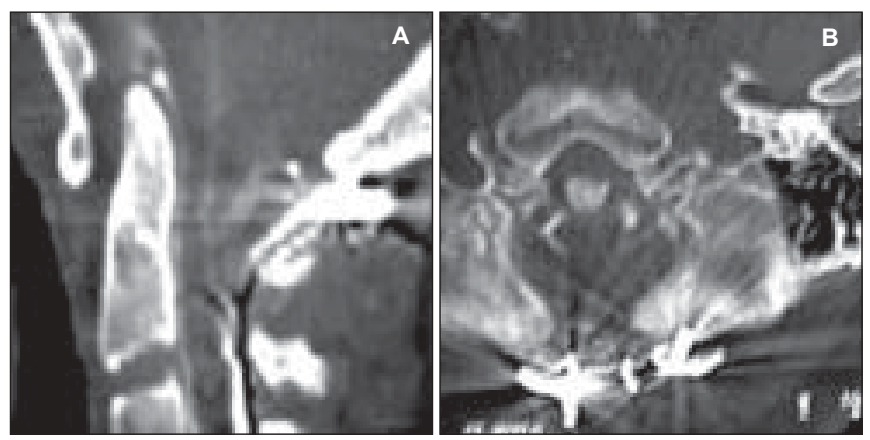

Figure 1: A. Sagittal reconstructed images of intrathecal contrast CT scan showing an irreducible AAD with Chiari I malformation in a patient who had initially undergone posterior fusion using sublaminar wires and strut and onlay bone grafts; and, B: Axial intrathecal contrast images showing the AAD causing residual anterior compression. A transoral and posterior decompression with $\mathrm{CR}$ fusion removed the residual compression and facilitated neurological recovery revealed residual cord compression from the posterior aspect. The posterior margin of the foramen magnum and the artificial arch were excised and a CR placed [Tables 2a and b].

The acquired $(n=4)$ conditions included tuberculous AAD [Figures 2a, b, c and d] $(\mathrm{n}=2)$; rheumatoid AAD $(\mathrm{n}=1)$; and traumatic C2-C3 listhesis [Table 2c].

The patients were clinically graded as: ${ }^{[1,24]}$ Grade I: independent without deficits except with hyperreflexia or neck pain $(n=6)$; Grade II: minor deficits but independent for daily needs ( $\mathrm{n}=15)$; Grade III: partially dependent on others for daily needs $(n=18)$; and, Grade IV: totally dependent $(\mathrm{n}=15)$. Improvement or deterioration was considered on the basis of changes in grades.

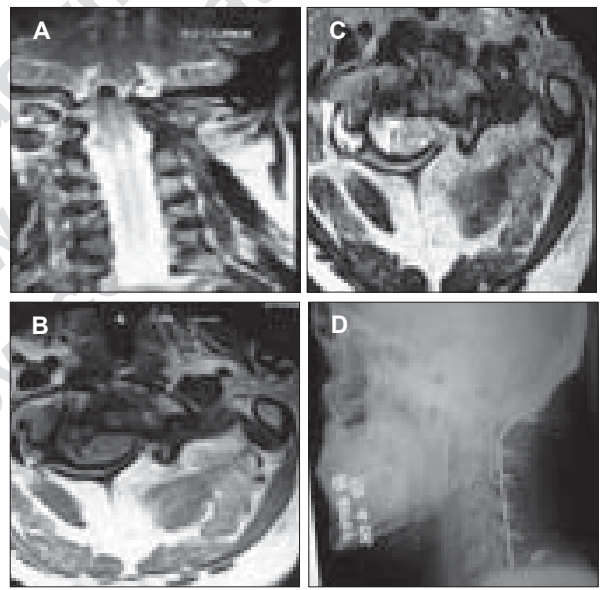

Figure 2: A. A T2-weighted coronal MRI showing the hyperintense signals (arrow) at the facet joint of C1-2 with lateral mass involvement; B. A T1; C. T2-weighted axial MRI showing the intensity changes (arrows) in the right lateral facet with the involvement of lateral masses; and, D. A postoperative radiograph showing the occipitocervical (Oc- C 4) contoured rod in place.

Table 1a: Associated anomalies with irreducible atlantoaxial dislocation
Associated anomalies

$\mathrm{BI}, \mathrm{C} 1 \mathrm{M}$ and syringomyelia C1M and syringomyelia $\mathrm{BI}$

$\mathrm{C} 1 \mathrm{M}$ and $\mathrm{BI}$

None

$\mathrm{C} 1 \mathrm{M}$

$\mathrm{BI}$ and syringomyelia

BI: basilar invagination, C1M: Chiari 1 malformation

Table 1b: Associated anomalies with reducible atlantoaxial dislocation

\begin{tabular}{lc}
\hline Associated anomalies & No. of patients (10) (\%) \\
$\mathrm{C} 1 \mathrm{M}$ and syringomyelia & $6(60)$ \\
$\mathrm{BI}, \mathrm{C} 1 \mathrm{M}$ and syringomyelia & 0 \\
$\mathrm{BI}$ & 0 \\
$\mathrm{BI}$ and C1M & 0 \\
$\mathrm{C} 1 \mathrm{M}$ & $1(10)$ \\
$\mathrm{Bl}$ and syringomyelia & 0 \\
None & $3(30)$ \\
\hline
\end{tabular}

No. of patients (40) (\%)

$13(32.5)$

$8(20)$

$7(17.5)$

$2(5)$

$5(12.5)$

$3(7.5)$

$2(5)$
BI: basilar invagination, C1M: Chiari 1 malformation 
$\overline{\text { Table 2a: Irreducible atlantoaxial dislocation with contoured rod }}$ stabilization $(n=40)$

Reasons for contoured rod

Associated C1M

No. of patients $(40)$

Occipitalized C1 and/or malformed

C1-2 posterior elements

AAD associated with rotatory $\mathrm{C} 1-2$ alignment

and compensatory subaxial spine scoliosis

Reoperations

24

8

3

5

AAD: Atlantoaxial dislocation, C: Cervical

Table 2b: Reducible atlantoaxial dislocation with contoured rod stabilization $(n=10)$

\begin{tabular}{lc}
\hline Reasons for contoured rod & No. of patients (10) \\
Associated C1M & 5 \\
Hypermobile AAD & 2 \\
Occipitalized C1 and/or malformed & \\
C1-2 posterior elements & 1 \\
Reoperations & 2
\end{tabular}

AAD: Atlantoaxial dislocation, C1M: Chiari 1 malformation, C: Cervical

Table 2c: Acquired anomalies with contoured rod stabilization $(n=4)$

\begin{tabular}{l}
\hline Reasons for contoured rod \\
CVJ tuberculosis with lateral \\
joint involvement \\
CVJ rheumatoid arthritis with \\
pannus extending to lateral C1-2 joints \\
Traumatic C2-3 listhesis with fracture \\
of posterior elements
\end{tabular}

CVJ: Craniovertebral junction, C: Cervical

\section{Radiology}

The radiological investigations included plain dynamic CVJ radiographs (neutral, flexion and extension) and cranio-spinal MRI. The postoperative ITCT imaging was used to determine adequacy of reduction, amount of decompression and stabilization. A postoperative MRI was not possible due to the use of stainless steel constructs.

Forty patients had irreducible AAD (patients who did not achieve reduction of $\mathrm{AAD}$ on extension or following traction) and 10 had reducible AAD. Basilar invagination was evaluated using McRae's line, Wackenheim's clival canal line, McGregor's line and Chamberlain's line. ${ }^{[1,3,5,16,25,26]}$ The extent of soft tissue involvement was noted in patients with tuberculous $(n=2)$ and rheumatoid $(\mathrm{n}=1)$ affliction. ${ }^{[16,25,27-30]}$

\section{Primary surgical management}

A preoperative Crutchfied's cervical traction was placed in our patients. All except three patients with irreducible AAD underwent TOD prior to the posterior procedure. The latter three patients also required a subsequent TOD following neurological deterioration at follow-up..$^{[3,18,31,32]}$

In the two patients with tuberculous $A A D$ and the one with rheumatoid AAD, TOD removed the tuberculous granulation or rheumatoid pannus, respectively. ${ }^{[16,27,29,30,34]}$

The occipitocervical fusion included Oc-C3 vertebral levels in 19 (35.2\%), Oc-C4 levels in 25 (46.3\%) and Oc-C5 levels in 10 (18.5\%) patients [Table 3].

\section{Operative technique}

The anterior decompression was performed in the supine position through the standard transpalatal, transpharyngeal route ${ }^{[1,3,18,26,32,33]}$ followed by CR under the same anesthesia.

A non-threaded, stainless steel Steinmann pin (4-5 $\mathrm{mm}$ diameter) was shaped and fixed to the occipital squama and the upper cervical laminae using braided Aesculap No. 5 stainless steel wires (Ethicon, Johnson and Johnson). Onlay autologous rib grafts were also placed [Figures 3a, b and c]. The construct cost was approximately 500 rupees (12 US dollars).

\section{Postoperative management}

Early ambulation was encouraged and hard cervical collar was worn for minimum of three months. The stabilization was assessed by visualizing a firm contact of the ends of the graft with bony occipitocervical surfaces (with or without new bone formation) without relative movement in flexion-extension radiological studies, at three months or more [Figure 4]. The serial clinicoradiological evaluations were performed at discharge and at follow-lip visits (three months, six months and then at yearly intervals) The patients having tuberculosis were continued on anti-tubercular treatment (18 months);

\begin{tabular}{lcc}
\hline & Table 3: Levels of occipitocervical fusion \\
\hline Level & Number & Percentage \\
Oc C3 & 19 & 35.2 \\
Oc C4 & 25 & 46.3 \\
Oc C5 & 10 & 18.5 \\
\hline
\end{tabular}

Oc: Occipital, C: Cervical

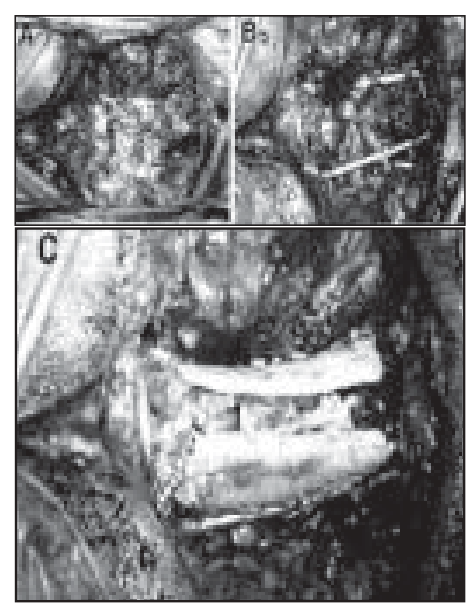

Figures 3: A-C. Operative steps showing placement of the occipitocervical contoured rod with onlay bone grafts 


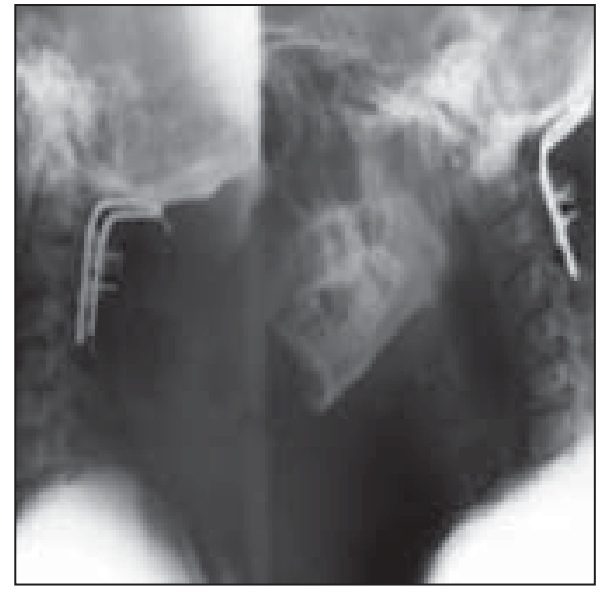

Figure 4: Dynamic (in flexion and extension) postoperative lateral cervical radiograph showing a stable bony union using a CR

and, the one with rheumatoid arthritis was continued on anti-rheumatoid therapy. ${ }^{[27,35]}$

\section{Results}

There were 15 patients in Grade II, 18 in Grade III and 15 in Grade IV. Only six were preoperatively in Grade I. Three of the latter group had an irreducible AAD, C1M and syringomyelia with a history of transient quadriparesis following minor trauma that improved subsequently with residual spasticity and/or hyperreflexia. The other three patients had reducible AAD (one each having hypermobile AAD; associated $\mathrm{C} 1 \mathrm{M}$ and syringomyelia; and deficient posterior $\mathrm{C} 1-2$ elements). Following surgery, 24 patients improved, 18 stabilized, four deteriorated and two died at the mean follow-up of $17.78 \pm 19.75$ (range: 2 -84) months [Table 4]. Six (11.1\%) patients were lost to follow-up.

Among the four patients with deterioration, one had hypermobile AAD, was in preoperative Grade I and developed minor deficits. The other three patients (one with reducible AAD, C1M and syringomyelia; two with irreducible AAD) were in preoperative Grade II. All three had initially undergone sublaminar fusion, had persisting posterior compression and improved following decompression and CR stabilization. The two mortalities occurred in Grade IV patients with irreducible $\mathrm{AAD}, \mathrm{C} 1 \mathrm{M}$ and syringomyelia with severe respiratory compromise who succumbed to bronchopneumonia.

There were 37 patients out of 46 patients (excluding six lost to follow-up and two deaths) with a follow-up long enough to assess for bony fusion (three months postsurgery). Thirty-one (83.8\%) of these patients achieved a stable bony fusion.

All the seven patients who underwent CR as a repeat procedure showed improvement. Nine patients in the series required a tracheostomy that was maintained for two to 22 months. The postoperative complications included wound gape following TOD $(n=4)$. They were managed conservatively and improved. There was vertebral artery injury with pseudoaneurysm formation in one patient with rheumatoid arthritis during the TOD. The complications following the posterior procedure were cerebrospinal fluid (CSF) leak in four and construct infection in two patients.

\section{Discussion}

\section{Technical considerations}

The inclusion of the occiput in the posterior fusion enhances stability in cases where extensive osteoligamentous destruction and/or instability of the occiput and upper cervical vertebrae coexist. ${ }^{[11,19,24,27]}$ In our patients with irreducible AAD, there was often an occiput- $\mathrm{C} 1$ and $\mathrm{C} 2-3$ fusion. In patients with tuberculous or rheumatoid affliction, there was a simultaneous lateral joint involvement. A summary of the various occipitocervical fusion techniques is presented in Table 5. ${ }^{[21,32]}$

The CR proved to be an effective and inexpensive method of providing a rigid stabilization. ${ }^{[36-39]}$ Significant kyphosis or scoliosis could be compensated for without significant sublaminar compression. ${ }^{[4,14,19,24,38]}$ There is a negligible risk of vertebral artery injury. The modern techniques, however, may have greater stability and CR has mechanical limitations in maintaining spinal alignment and deformity correction. It requires an intact lamina for fixation; does not include the afflicted spinal level; requires longer fusion than decompression

\begin{tabular}{|c|c|c|c|c|c|c|c|c|c|}
\hline $\begin{array}{l}\text { Follow-up grade } \\
\text { Preoperative grade }\end{array}$ & I & II & III & IV & $\begin{array}{l}\text { Lost to } \\
\text { follow-up }\end{array}$ & Death & Improved & Stabilized & Deteriorated \\
\hline $\begin{array}{l}l \\
n=6\end{array}$ & 4 & 1 & 0 & 0 & 1 & 0 & 0 & 4 & 1 \\
\hline $\begin{array}{l}\text { II } \\
n=15\end{array}$ & 2 & 8 & 2 & 1 & 2 & 0 & 2 & 8 & 3 \\
\hline $\begin{array}{l}\text { III } \\
n=18\end{array}$ & 1 & 12 & 3 & 0 & 2 & 0 & 13 & 3 & 0 \\
\hline $\begin{array}{l}\text { IV } \\
n=15\end{array}$ & 1 & 7 & 1 & 3 & 1 & 2 & 9 & 3 & 2 \\
\hline $\begin{array}{l}\text { Total } \\
\mathrm{n}=54\end{array}$ & 9 & 23 & 11 & 5 & 6 & 2 & 24 & 18 & 6 \\
\hline
\end{tabular}


Table 5: Review of methods of occipitocervical fusion ${ }^{[3,10,14,22,47]}$

\begin{tabular}{|c|c|c|c|}
\hline Method & Source & Advantages & Disadvantages \\
\hline $\begin{array}{l}\text { In situ fusion with onlay } \\
\text { bone graft }\end{array}$ & $\begin{array}{l}\text { Lee et al., 1984 } \\
\text { Ransford et al., 1986 } \\
{[19]}\end{array}$ & Simplicity. & $\begin{array}{l}\text { Lack of rigid stabilization. No } \\
\text { correction of kyphotic deformity. }\end{array}$ \\
\hline Methylmethacrylate aided bone fusion & $\begin{array}{l}\text { Bryan et al., } 1982^{[12]} \\
\text { Zygmunt et al..,1988 } \\
\text { Clark et al.,1989] }\end{array}$ & Simplicity. & $\begin{array}{l}\text { Wound infection. } \\
\text { No correction of kyphotic deformity. }\end{array}$ \\
\hline Occipitocervical plates and screws & $\begin{array}{l}\text { Abumi et al., 1999[10] } \\
\text { Cregan, 1996 } \\
\text { Heywood et al., 1988 } \\
\text { Grob et al., } 1991^{[17]}\end{array}$ & $\begin{array}{l}\text { Rotational stability provided and } \\
\text { rigid internal fixation without } \\
\text { using sublaminar wires. }\end{array}$ & $\begin{array}{l}\text { Technically demanding and } \\
\text { screws prone to loosening } \\
\text { and breaking out. }\end{array}$ \\
\hline $\begin{array}{l}\text { Malleable rod with segmental } \\
\text { wire fixation }\end{array}$ & $\begin{array}{l}\text { Ransford et al., } 1986^{[19]} \\
\text { Itoh et al., } 1988^{[22]} \\
\text { Sakou et al., 1989 } \\
\text { Fehlings et al., } 1993^{[14]}\end{array}$ & $\begin{array}{l}\text { Simplicity; correction of kyphotic } \\
\text { deformity, extremely rigid and } \\
\text { flexibility of angle. }\end{array}$ & $\begin{array}{l}\text { Incidence of CSF leak may be } \\
\text { marginally higher, long } \\
\text { segment fusion. }\end{array}$ \\
\hline $\begin{array}{l}\text { Transarticular screws and } \\
\text { lateral mass fixation }\end{array}$ & $\begin{array}{l}\text { Stillerman et al., 1993 } \\
\text { Goel et al.,1994] } \\
\text { Lu et al., 1998 } \\
\text { Gluf et al., } 2005^{[14,15]}\end{array}$ & $\begin{array}{l}\text { Decreased risk of neural injury } \\
\text { and retro displacement of } \\
\text { ventral structures. }\end{array}$ & $\begin{array}{l}\text { Technically demanding and } \\
\text { screws prone to loosening, } \\
\text { difficult screw purchase and } \\
\text { injuring vertebral artery. }\end{array}$ \\
\hline
\end{tabular}

levels; and has the potential risk of dural penetration by wires.

Most patients had congenital AAD and the lateral joints were frequently asymmetrical with often vertically oriented occipito C1-2 facets. In another series, 78.6 $\%$ of pediatric patients with congenital AAD had asymmetrical or vertical joints. ${ }^{[40]}$ In these situations, newer methods involving lateral masses or transarticular screws have higher risk of abnormal placement of the construct. Even with normal joints, the incidence of arterial injury or faulty placement is high $(2-5 \%$ in various series). ${ }^{[5,15,22,41,42]}$

\section{Considerations in congenital anomalies}

The extent of anterior resection may vary from from drilling the clivus in $\mathrm{BI}$ to removal of the $\mathrm{C} 2-3$ body and this determines the levels of elements included during posterior fusion. ${ }^{[1,3,32]}$

We usually performed modified Brooks' technique for reducible AAD. ${ }^{[1,3,33]}$ In some of these patients, however, the amount of neck extension required to achieve an adequate C1-2 reduction may severely compromise the desired area of surgical exposure. In CR stabilization, the neck may be maintained in neutral postion with an in situ stabilization of the vertebral bodies performed. In the two patients with hypermobile AAD with os odontoideum, CR was considered safer than the Brooks' technique as there was danger of the posterior $\mathrm{C} 1 \mathrm{arch}$ being pulled backwards into the cervical canal in the latter technique.

\section{Considerations in acquired pathologies}

Behari et al. ${ }^{[27]}$ have recommended conservative management in good grade and aggressive surgical therapy for poor grade patients with tuberculous AAD. Gupta et al., ${ }^{[6]}$ in fact, have recently questioned the need of surgery. Nannapaneni et al. ${ }^{[29]}$ and Crockard ${ }^{[31,43]}$ have emphasized increased incidence of short segment fusion failure in rheumatoid affliction. With extensive osteo-ligamentous destruction, CR stabilization helps in achieving a long segment fusion. During TOD in our case, of rheumatoid AAD, the medially displaced vertebral artery was inadvertently injured. The resultant traumatic pseudoaneurysm had to be coiled. Fortunately, there were sufficient collaterals and the patient had no deficits.

\section{Considerations during revision surgery}

Patients with C1M should be investigated for an associated AAD. ${ }^{[5]}$ Three such patients underwent only posterior decompression at another center. Following neurological deterioration those with irreducible AAD ( $n=2)$ underwent TOD and CR and the one with reducible AAD underwent CR stabilization. Three patients with residual compression following sublaminar wiring required repeat decompression and CR placement.

It is reported that long segment constructs cause a 10to 20- degree loss of lateral bending, flexion-extension and axial rotation. ${ }^{[6,9,11,13,14,19,36,37]}$ In our patients with congenital AAD, this was not disabling as movements were already restricted due to asymmetric or hypoplastic facet joints. In patients with acquired disorders, severe pain, muscle spasm and lateral joint involvement had already severely restricted neck movements. ${ }^{[38,39]}$

To conclude, CR stabilization forms an economical, simple and effective method of occipitocervical stabilization. In cases of asymmetrically disposed or diseased facet joints and lateral masses this method may in fact be the best way of securing stability.

\section{References}

1. B ehari S, B hargava V, N ayak S, K iran K umar MV, B anerji D, Chhabra DK, \&al. Congenital reducible atlantoaxial dislocation: Classification and surgical considerations. Acta N eurochir (Wien) 2002;144:1165-77.

2. Hensinger RN . Osseous anomalies of the craniovertebral junction. Spine 1986;11:323-33.

3. J ain VK, B ehari S. Congenital atlanto-axial dislocation. Some lessons 
learnt. N eurol India 2002;50:386-97.

4. L uque $E R$. The anatomic basis and development of segmental spinal instrumentation. Spine 1982;7:256-9.

5. Menezes AH, VanGilder J C, Graf CJ , MCD onnell DE. Craniocervical anomalies. A comprehensive surgical approach. J Neurosurg 1980;53:444-55.

6. Grob D, Dvorak J, Panjabi M, Froehlich M, Hayek J. Posterior occipitocervical fusion. A preliminary report of a new technique. Spine 1991;16:S17-24.

7. L ee SC, Chun SY, L eong J C. Experience of posterior surgery in atlantoaxial instability. Spine 1984;9:231-9.

8. Sasso RC, J eanneret B, F ischer K, Magerl F. Occipitocervical fusion with posterior plate and screw instrumentation. A long-term follow-up study. Spine 1994;19:2364-8.

9. Vender J R, Rekito AJ, H arrison SJ, MCD onnell DE. The evolution of posterior cervical and occipitocervical fusion and instrumentation. N eurosurg Focus 2004;16:E 9.

10. Abumi K, Takada T, Shono Y, Kaneda K, Fujiya M. Posterior occipitocervical reconstruction using cervical pediclescrews and plate-rod systems. Spine 1999;24:1425-34.

11. A postolides PJ, Dickman CA, Golfinos J G, Papadopoulos SM, Sonntag VK. Threaded steinmann pin fusion of the craniovertebral junction. Spine 1996;21:1630-7.

12. Bryan WJ, Inglis AE, Sculco TP, Ranawat CS. Methylmethacrylate stabilization for enhancement of posterior cervical arthrodesis in rheumatoid arthritis. J B one J oint Surg Am 1982;64:1045-50.

13. Deutsch $\mathrm{H}, \mathrm{H}$ aid RW J r, Rodts GE J r, M ummaneni PV. Occipitocervical fixation: $L$ ong-term results. Spine 2005;30:530-5.

14. Fehlings M G, Cooper PR, E rrico T] . Posterior plates in the management of cervical instability: L ong-term results in 44 patients. J Neurosurg 1994:81:341-9.

15. Gluf WM , Schmidt MH, A pfelbaum RI. Atlantoaxial transarticular screw fixation: A review of surgical indications, fusion rate, complications and lessons learned in 191 adult patients. J N eurosurg Spine 2005;2:155-63.

16. Goel A, Sharma P. Craniovertebral realignment for basilar invagination and atlantoaxial dislocation secondary to rheumatoid arthritis. N euro India 2004;52:338-41.

17. Grob D, Dvorak J, Panjabi MM, Antinnes J A. The role of plate and screw fixation in occipitocervical fusion in rheumatoid arthritis. Spine 1994;19:2545-51.

18. J ain VK, Mittal P, B anerji D, B ehari S, Acharya R, Chhabra DK Posterior occipitoaxial fusion for atlantoaxial dislocation associated with occipitalized atlas. J N eurosurg 1996;84:559-64

19. Ransford AO, Crockard HA, POzo J L, Thomas NP, N elson IW.Craniocervical instability treated by contoured loop fixation. J B one J oint Surg Br 1986;68:173-7.

20. Sakou T, Kawaida H, Morizono Y, M atsunaga S, Fielding J W. Occipitoatlantoaxial fusion utilizing a rectangular rod. Clin Orthop R elat Res 1989:239:136-44.

21. I toh $\mathrm{T}$, Tsuji $\mathrm{H}, \mathrm{K}$ atoh $\mathrm{Y}$, Yonezawa $\mathrm{T}$, K itagawa $\mathrm{H}$. Occipito-cervical fusion reinforced by Luque's segmental spinal instrumentation for rheumatoid diseases. Spine 1988;13:1234-8.

22. Gluf WM, B rockmeyer DL. Atlantoaxial transarticular screw fixation: A review of surgical indications, fusion rate, complications and lessons learned in 67 pediatric patients. I N eurosurg Spine 2005;2:164-9.

23. Goel A, L aheri V. Plate and screw fixation for atlanto-axial subluxation. Acta N eurochir (Wien) 1994:129:47-53.

24. Malcolm GP, Ransford AO, Crockard H A. Treatment of non-rheumatoid occipitocervical instability. I nternal fixation with the $\mathrm{H}$ artshill-R ansford loop. J B one J oint Surg B r 1994;76:357-66.

25. Goel A, Pareikh S, Sharma P. Atlantoaxial joint distraction for treatment of basilar invagination secondary to rheumatoid arthritis. N eurol India 2005:53:238-40.

26. Wackenheim A. Radiological diagnosis of congenital forms, intermittent forms and progressive forms of stenosis of the spinal canal at the leve of the atlas. Acta Radiol Diagn 1969;9:481-6.

27. B ehari S, Nayak SR, B hargava V, B anerji D, Chhabra DK, J ain VK. Craniocervical tuberculosis: Protocol of surgical management. N eurosurgery 2003;52:72-81.

28. Cregan J C. Internal fixation of the unstable rheumatoid cervical spine. Ann R heum Dis 1966;25:242-52.

29. N annapaneni R, B ehari S, Todd NV. Surgical outcome in rheumatoid Ranawat Class III b myelopathy. N eurosurgery 2005;56:706-15.

30. Ranawat CS, O'L eary $P$, Pellicci $P$, Tsairis $P$, Marchisello $P$, D orr L Cervical spine fusion in rheumatoid arthritis. J B one J oint Surg Am 1979;61:1003-10.

31. Crockard H A, Pozo J L, Ransford AO, Stevens J M, K endall BE, E ssigman WK. Transoral decompression and posterior fusion for rheumatoid atlanto-axial subluxation. J B one J oint Surg B r 1986;68:350-6.

32. Dickman CA, L ocantro J , Fessler RG. Theinfluence of transoral odontoid resection on stability of the craniovertebral junction. J Neurosurg 1992;77:525-30

33. J ain VK, B ehari S, B hargava V. Management of fixed atlantoaxial dislocation. Prog Clin N eurosci 1999;14:77-93.

34. Clark CR, Goetz DD, Menezes AH. Arthrodesis of the cervical spine in rheumatoid arthritis. J B one J oint Surg Am 1989;71:381-92.

35. Gupta SK, Mohindra S, Sharma BS, Gupta R, Chhabra R, Mukherjee $K K, \notin$ al. Tuberculosis of the craniovertebral junction: Is surgery necessary? N eurosurgery 2006;58:1144-50.

36. Hurlbert RJ , Crawford NR, Choi WG, Dickman CA. A biomechanical evaluation of occipitocervical instrumentation: Screw compared with wire fixation. J N eurosurg 1999;90:84-90.

37. Melcher R P, Puttlitz CM, K leinstueck F S, L otz J C, H arms I, B radford DS. B iomechanical testing of posterior atlantoaxial fixation techniques. Spine 2002;27:2435-40.

38. Oda I, Abumi K, Sell LC, H aggerty CJ , Cunningham BW, M CAfee PC. $B$ iomechanical evaluation of five different occipito-atlanto-axial fixation techniques. Spine 1999;24:2377-82.

39. White AA $3^{\text {rd }}$, Panjabi MM. The clinical biomechanics of the occipito atlantoaxial complex. Orthop Clin N orth Am 1978;9:867-78.

40. Salunke P, B ehari S, K irankumar MV, Sharma MS, J aiswal AK, J ain VK. Pediatric congenital atlantoaxial dislocation: D ifferences between the irreducible and reducible varieties. I N eurosurg 2006;104:115-22.

41. Reilly TM, Sasso RC, Hall PV. Atlantoaxial stabilization: Clinical comparison of posterior cervical wiring technique with transarticular screw fixation. J Spinal Disord Tech 2003;16:248-53.

42. Stillerman $C B$, Wilson J A. Atlanto-axial stabilization with posterior transarticular screw fixation. technical description and report of 22 cases. N eurosurgery 1993;32:948-55.

43. Crockard HA, Calder I, Ransford AO. One-stage transoral decompression and posterior fixation in rheumatoid atlanto-axial subluxation. J B one J oint Surg B r 1990;72:682-5.

44. Zygmunt SC, L junggren B, Alund M, B rattstrom $H$, Saveland HG, $\mathrm{H}$ oltas $\mathrm{S}, \mathbb{A}$ al. Realignment and surgical fixation of atlanto-axial and subaxial dislocations in rheumatoid arthritis (RA) patients. Acta N eurochir Suppl (Wien) 1988;43:79-84.

45. H eywood AW, L earmonth ID, Thomas M. I nternal fixation for occipitocervical fusion. J B one J oint Surg Br 1988;70:708-11.

46. L U J, E braheim NA, Yang H, Heck BE, Yeasting RA. Anatomic considerations of anterior transarticular screw fixation for atlantoaxial instability. Spine 1998;23:1229-36.

47. Chandramouli B A, D as BS. Occipitocervical fusion using contoured rod. In: J ain VK, B ehari S, editors. Craniovertebral junction anomalies, The Indian experience. Army Printing Press: L ucknow; 1997. p. 51-6.

Accepted on 11-06-2007

Source of Support: Nil, Conflict of Interest: None declared. 